\title{
Increasing solubility of metal silicates by mixed polymeric antiscalants
}

\author{
Gokhan Topcu $^{\mathrm{a}}$, Aslı Çelik ${ }^{\mathrm{a}}$, Ali Kandemir ${ }^{\mathrm{a}}$, Alper Baba ${ }^{\mathrm{b}}$, Hasan Sahin ${ }^{\mathrm{c}, \mathrm{d}}$, Mustafa M. Demir ${ }^{\mathrm{a}, *}$ \\ a Department of Materials Science and Engineering, İzmir Institute of Technology, 35430, Gülbahçe, Urla, İzmir, Turkey \\ b Department of Civil Engineering, İzmir Institute of Technology, 35430, Gülbahçe, Urla, Izmir, Turkey \\ c ICTP-ECAR Eurasian Centre for Advanced Research, İzmir Institute of Technology, 35430, Gülbahçe, Urla, İzmir, Turkey \\ d Department of Photonics, İzmir Institute of Technology, 35430, Gülbahçe, Urla, İzmir, Turkey
}

\section{A R T I C L E I N F O}

\section{Keywords:}

Antiscalant

Chelation

$$
\text { DFT }
$$

Geothermal

Metal silicate

Stabilizer

\begin{abstract}
A B S T R A C T
The increase of silicate solubility is a big challenge for both hot and cold water because it reduces the deposition of metal silicates frequently observed in such systems and causes operational obstacles. The deposition of silicate coats the inner surface of the pipelines in an uncontrolled manner and reduces the harvesting of energy from brines. In this work, the solubility performance of two commercial water-soluble polymeric agents (poly(ethylene glycol) (PEG) and poly(vinyl alcohol) (PVA)) of various molecular weights employing dosage from 25 to $100 \mathrm{mg} / \mathrm{L}$ was examined. Along with dispersant-type antiscalant, poly(acrylamide) (PAM), poly(vinylsulfonic acid, sodium salt) (PVSA), and poly(vinylphosphonic acid) (PVPA) having chelating acidic groups were employed. Metal silicate deposits were obtained artificially in the lab-scale pressurized reactor. The experimental conditions employed were quite similar to a model power plant located in Çanakkale, Turkey. The concentration of dissolved silica was increased from 130 to $420 \mathrm{mg} / \mathrm{L}$ when $100 \mathrm{mg} / \mathrm{L}$ PEG 1500 and $25 \mathrm{mg} / \mathrm{L}$ PVSA were employed as a mixture. For the atomic-level understanding of the interaction of chelating groups with metal cations, DFT calculations were performed too.
\end{abstract}

\section{Introduction}

Metal silicate scaling is a frequently observed obstacle to the utilization of hot geothermal/petroleum fields and cold industrial water systems. Metal silicates are formed by the polymerization of silicate ions in the presence of metal cations via condensation polymerization. The accumulation of metal silicates on the surface of parts such as pipes, separating vessels and heat exchangers interferes with the flow of the system, hence reducing the efficiency of the plants (Gallup, 2002; Potapov et al., 2001). Since silicate scaling is dense and mechanically resistant, strong acids particularly HF are often employed to disintegrate the $\mathrm{Si}-\mathrm{O}$ bond and eventually the silicate deposit (Demadis et al., 2011a, b). However, working in an acidic environment is risky because it may lead to serious corrosion or health issues unless the concentration and chemical structure of the acid are selected meticulously (Demir et al., 2014; Zhang et al., 2011). Increasing the solubility of silicates by soft antiscalants appears to be a promising remedy to minimize of scaling (Gallup, 2002; Gallup and Barcelon, 2005).

A limited number of studies on increasing the solubility of metal silicates exists (Corsi, 1986; Demadis et al., 2012a, b; Gallup, 1998, 2002, 2009; Gallup and Barcelon, 2005; Spinde et al., 2011), and which focus on mitigating the scaling via stabilization of the silicic acid by dispersion and/or chelation. The working principle is based on the stabilization of silica colloids, which are considered to be the main component of the metal silicate deposits. Polymeric molecules stabilize the colloids (van der Waals forces or hydrogen bonding) so that they are prevented from aggregating/agglomerating of the colloids. For instance, Preari et al. (2014) employed PEG, which is mostly known as a non-ionic surfactant, with various molecular weights (from 1.55 to $20 \mathrm{~kg} / \mathrm{mol}$ ) and revealed that PEG interacts with silica species via $\mathrm{H}$ bonding at neutral conditions. On the other hand, another study focused on the removal of an ionic substance from the medium by electrostatic interaction (Palencia et al., 2009; Porcelli and Judd, 2010). Organic compounds containing positively charged groups have often been preferred as ligands. These compounds include protonated primary, secondary or tertiary amines (Danilovtseva et al., 2011; Demadis et al., 2008; Spinde et al., 2011); amide moieties (Demadis and Neofotistou, 2007); and phosphonium (Demadis et al., 2012a, b), while the functional groups are reactive silica species. The polymers reported so far are molecules intended merely for the improvement of silica solubility; however, similar attempts for the metal-silicates aiming at metal solubility have not been examined (Topçu et al., 2017). The effect of metal cations, known as catalysts for silica polycondensation (Demadis et al., 2012a, b), on metal-silicate formation was reduced by

\footnotetext{
* Corresponding author.

E-mail address: mdemir@iyte.edu.tr (M.M. Demir).
} 
using polymers with pendant groups that are capable of chelating metals.

The Tuzla Geothermal Power Plant (TGPP) in Çanakkale, Turkey, was chosen as a model binary system to study metal silicate scaling. This geothermal site is located in the volcanic zone and allows the generation of 7.5 MWe from a connate water reservoir. Iron-magnesium silicate (Fe, Mg silicate) is a deposit heavily formed in this plant. The level of silica concentration is $\sim 200 \mathrm{mg} / \mathrm{L}$; note that some organic acids are used for $\mathrm{pH}$ modification (Baba et al., 2015). A Fe, Mg silicate deposit can be prepared synthetically in the lab using a pressurized autoclave, starting from chloride-rich precursors in the presence of silicate and carbonate salts.

In this study, poly(ethylene glycol) (PEG) and poly(vinyl alcohol) (PVA), with various molecular weights, are employed as silica-targeted metal-silicate antiscalants in several dosages. The solubility performance of PEG and PVA (at 25, 50, and $100 \mathrm{mg} / \mathrm{L}$ ) was investigated from the concentration of leftover silica species in liquid phase after centrifugation of the reaction mixture. To enhance the antiscaling efficiency by eliminating metal cations, additional polymeric co-antiscalants containing acidic chelating groups were used, such as poly (acrylamide) (PAM) (Girma et al., 2005, 2006), sodium salt of poly (vinylsulfonic acid) (PVSA) (Palencia et al., 2009), and poly(vinylphosphonic acid) (PVPA) (Rivas et al., 2004). Since metal-silicate scaling is more common in hot/cold water systems, experiments were carried out in a closed reactor system as an operational system to simulate the real field conditions in terms of salinity of brine, pressure, and temperature of the plants.

\section{Experimental}

\subsection{Materials}

$\mathrm{FeCl}_{2} \cdot 4 \mathrm{H}_{2} \mathrm{O}$ and $\mathrm{MgCl}_{2} \cdot 6 \mathrm{H}_{2} \mathrm{O}$ were purchased from Merck (Kenilworth, NJ, USA), $\mathrm{CaCl}_{2}$ and $\mathrm{Na}_{2} \mathrm{CO}_{3}$ were obtained from SigmaAldrich (St. Louis, MO, USA). $\mathrm{Na}_{2} \mathrm{SiO}_{3}$ (35.5 wt.\% in $\mathrm{H}_{2} \mathrm{O}$ ) was employed (Carl Roth, Karlsruhe, Germany) as a silica source. The various molecular weights of PEG (Mw: $0.4,1.5$, and $6.0 \mathrm{~kg} / \mathrm{mol})$ and PVA $(M w$ : 40, 50, and $92 \mathrm{~kg} / \mathrm{mol}$ ) were supplied by Sigma-Aldrich. PAM, PVSA, and PVPA were synthesized in our lab to employ as co-antiscalants and detailed information regarding the synthesis was given in a previous study (Topçu et al., 2017). All the antiscalants were dissolved in $50 \mathrm{~mL}$ $\mathrm{dH}_{2} \mathrm{O}$ and their dosage was fixed to 25,50 , and $100 \mathrm{mg} / \mathrm{L}$. The molecular structure of inhibitors is presented in Fig. 1. The deionized water
Table 1

The concentration $(\mathrm{mg} / \mathrm{L})$ of the components in artificial brine for the control experiment before and after the reaction.

\begin{tabular}{llllll}
\hline & {$\left[\mathrm{Fe}^{2+}\right]$} & {$\left[\mathrm{Mg}^{2+}\right]$} & {$\left[\mathrm{Ca}^{2+}\right]$} & {$\left[\mathrm{Na}^{+}\right]$} & {$\left[\mathrm{SiO}_{2}\right]$} \\
\hline Before Reaction & 927 & 404 & 1330 & 1912 & 598 \\
After Reaction & $3.5^{*}$ & 48 & 270 & 332 & 135 \\
\hline
\end{tabular}

Temperature $\left({ }^{\circ} \mathrm{C}\right): 137.6$ - Pressure (bar): $3.2,{ }^{*} \Sigma\left[\mathrm{Fe}^{2+/ 3+}\right]$.

$\left(18.2 \mathrm{M} \Omega \mathrm{cm}^{-1}\right.$ at $\left.25^{\circ} \mathrm{C}\right)$ used in all experiments was produced by a Milli-Q Advantage Water Purification System (Merck).

\subsection{Methods}

Metal-silicate deposits were synthesized in an autoclave reactor system (Büchi Glas Uster, mini clave 075 model, Switzerland). First, a synthetic brine solution was prepared in $200 \mathrm{~mL}$ deionized water using $132 \mathrm{mg} \mathrm{FeCl}_{2} 4 \mathrm{H}_{2} \mathrm{O}, 135 \mathrm{mg} \quad \mathrm{MgCl}_{2} 6 \mathrm{H}_{2} \mathrm{O}, 240 \mathrm{mg} \quad \mathrm{CaCl}_{2}, 70 \mathrm{mg}$ $\mathrm{Na}_{2} \mathrm{CO}_{3}$, and $440 \mu \mathrm{L} \mathrm{Na} \mathrm{SiO}_{3}$ (Table 1). The solution was loaded into the reactor under ambient conditions. Subsequently, the mixture was heated to $137.6{ }^{\circ} \mathrm{C}$ at 3.2 bar pressure. The technical drawing of the reactor is shown in Fig. 2. After a heat and pressure treatment for $\approx 45 \mathrm{~min}$, an antiscalant solution was added to the brine solution. The mixture was ejected to plastic vessel through a Teflon pipe to cool down in ice bath. A sudden decrease in the pressure and temperature of the reaction causes the precipitation of an artificial deposit. The resulting reaction mixture is centrifuged at $6000 \mathrm{rpm}$. The deposit is isolated for analysis. The leftover decantate solution was analyzed using UV-spectrophotometry (Hach DR 5000, Loveland, CO, USA) for molybdate reactive silica and an Inductively Coupled Plasma Mass Spectroscopy (ICP-MS, Agilent 7500 CE Octopole, Santa Clara, CA, USA) for metal cation concentrations. The $\mathrm{pH}$ regime of the solution was examined at room temperature by using a multiparameter (pHenomenal MU $6100 \mathrm{~L}$, VWR International, Vienna, Austria)

Spectrometric methods are utilized on the liquid phase for precise examination of the performance of the polymers in silica formation. For instance, the silicomolybdate method is a facile way used in UV spectroscopy to detect reactive silica species, including monomeric, dimeric, and perhaps trimeric forms of silica (Coradin et al., 2004; Iler, 1979). This method is based on the principle that ammonium molybdate reacts with reactive silica (especially monomer form) and any phosphate group at low $\mathrm{pH}$ resulting in yellow products. The molybdophosphoric

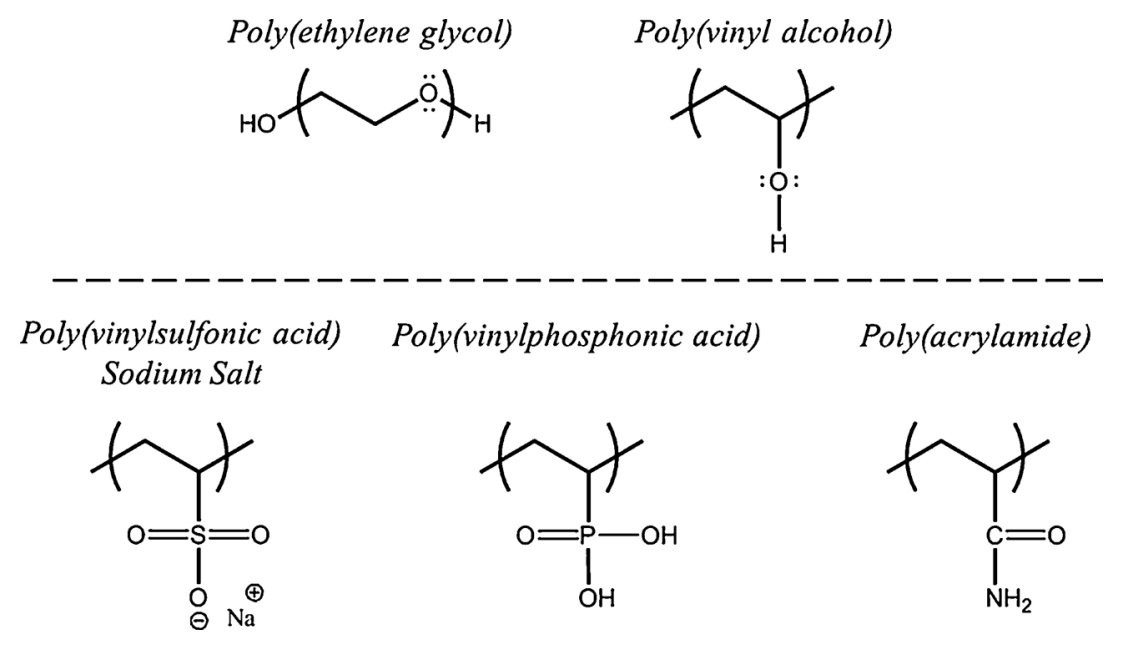

Fig. 1. Molecular structures of polymeric antiscalants. 


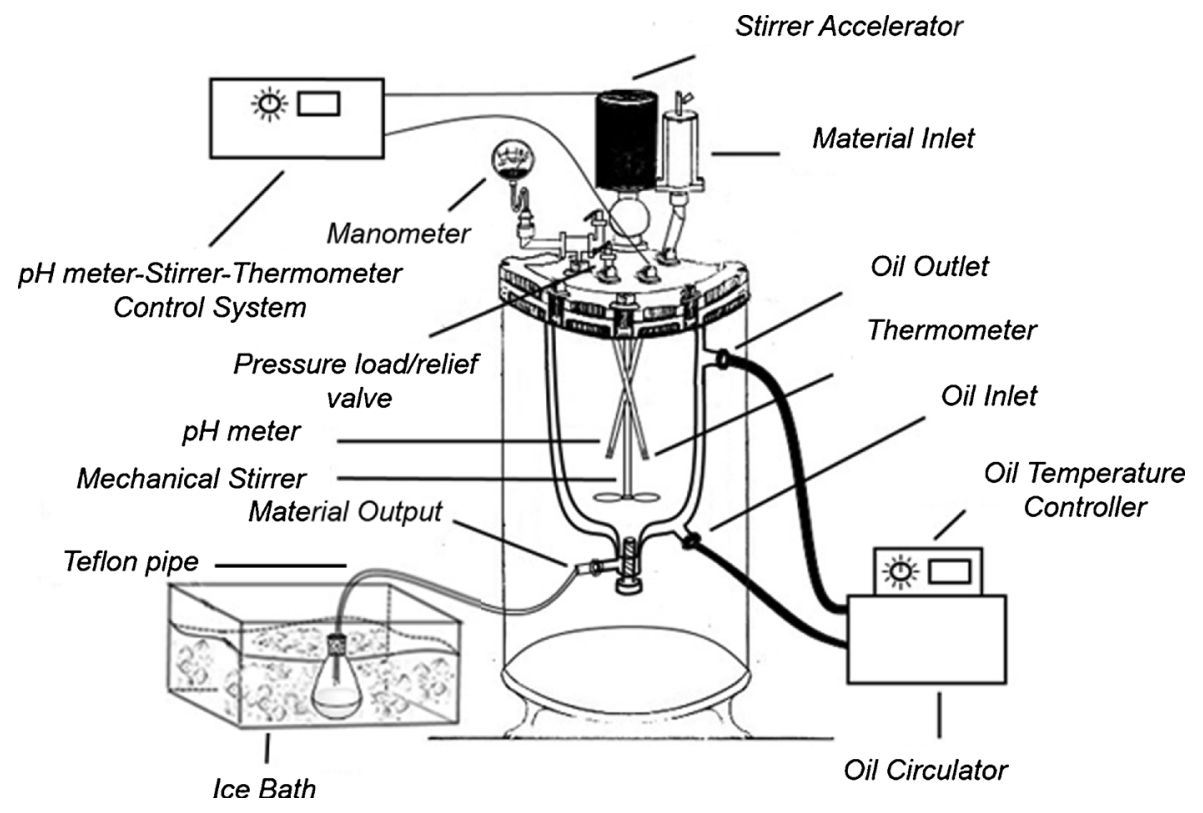

Fig. 2. Schematic representation of autoclave system (Çelik et al., 2017).

acid formation is eliminated by adding oxalic acid to prevent any color interference from the phosphates, hence the resulting color will be caused by the silicomolybdate complex only. Therefore, reported silica concentration throughout the text is molybdate reactive silica (Icopini et al., 2005).

The solubility performance of silicates in the presence of polymeric antiscalants was determined by the concentration of molybdate reactive silica. For quantitative analysis, the following equation was used:

$n=\frac{C_{2}-C_{1}}{C_{\text {initial }}-C_{1}}$

where $C_{1}$ and $C_{2}$ refer to molybdate reactive silica after the autoclave experiment without and with antiscalant, respectively. The initial silica concentration is expressed as $C_{\text {initial }}$ and observed as $598 \mathrm{mg} / \mathrm{L}$. Table 2 presents the results of trials containing information regarding the type of polymeric antiscalant, dosage, and solubility performance.
The crystal properties of deposits were characterized by X-ray diffraction spectroscopy (XRD; X'Pert Pro, Philips, Eindhoven, The Netherlands), while their morphology was monitored by using a scanning electron microscope (SEM; 300VP, Carl Zeiss, Oberkochen, Germany). The vibrational characteristics of deposits were examined by both Raman (Horiba, XploRA PLUS, Kyoto, Japan) and ATR FT-IR (PerkinElmer, Frontier, MA, US) spectroscopy. Elemental composition of the deposit was determined using X-ray fluorescence spectroscopy (XRF, Spectro iQ II, Kleve, Germany).

\subsection{Computational details}

To provide complete information on the structural characteristics and selective metal ion-chelating performance of the molecules, quantum mechanical calculations were performed using density functional theory (DFT). The Vienna ab initio simulation package (VASP)

Table 2

Information regarding the all antiscalants and the experiments along with their solubility performance.

\begin{tabular}{|c|c|c|c|c|c|}
\hline Antiscalant I & Antiscalant II & $\begin{array}{c}\text { Molecular } \\
\text { Weight (kDa) }\end{array}$ & $\begin{array}{l}\text { Dosage I } \\
(\mathrm{mg} / \mathrm{L})\end{array}$ & $\begin{array}{c}\text { Dosage II } \\
(\mathrm{mg} / \mathrm{L})\end{array}$ & $\begin{array}{c}\text { Solubility } \\
\text { performance (\%) }\end{array}$ \\
\hline \multirow[t]{3}{*}{ PEG400 } & - & & 25 & - & 6.5 \\
\hline & & 0.4 & 50 & & 12.7 \\
\hline & & & 100 & & 15.5 \\
\hline \multirow[t]{3}{*}{ PEG1500 } & - & & 25 & - & 14.5 \\
\hline & & 1.5 & 50 & & 38 \\
\hline & & & 100 & & 51.5 \\
\hline \multirow[t]{3}{*}{ PEG6000 } & - & & 25 & - & 15.5 \\
\hline & & 6.0 & 50 & & 29.1 \\
\hline & & & 100 & & 25.7 \\
\hline \multirow[t]{3}{*}{ PVA40 } & - & & 25 & - & 14 \\
\hline & & $30-50$ & 50 & & 19.1 \\
\hline & & & 100 & & 22.5 \\
\hline \multirow[t]{3}{*}{ PVA50 } & - & & 25 & - & 15.5 \\
\hline & & $30-70$ & 50 & & 20 \\
\hline & & & 100 & & 23.4 \\
\hline \multirow[t]{3}{*}{ PVA92 } & - & & 25 & - & 24.5 \\
\hline & & $88-97$ & 50 & & 20.4 \\
\hline & & & 100 & & 25.7 \\
\hline PEG1500 & PVSA & - & 100 & 25 & 61.0 \\
\hline PEG1500 & PAM & - & 100 & 100 & 48.5 \\
\hline PEG1500 & PVPA & - & 100 & 100 & 43.5 \\
\hline
\end{tabular}



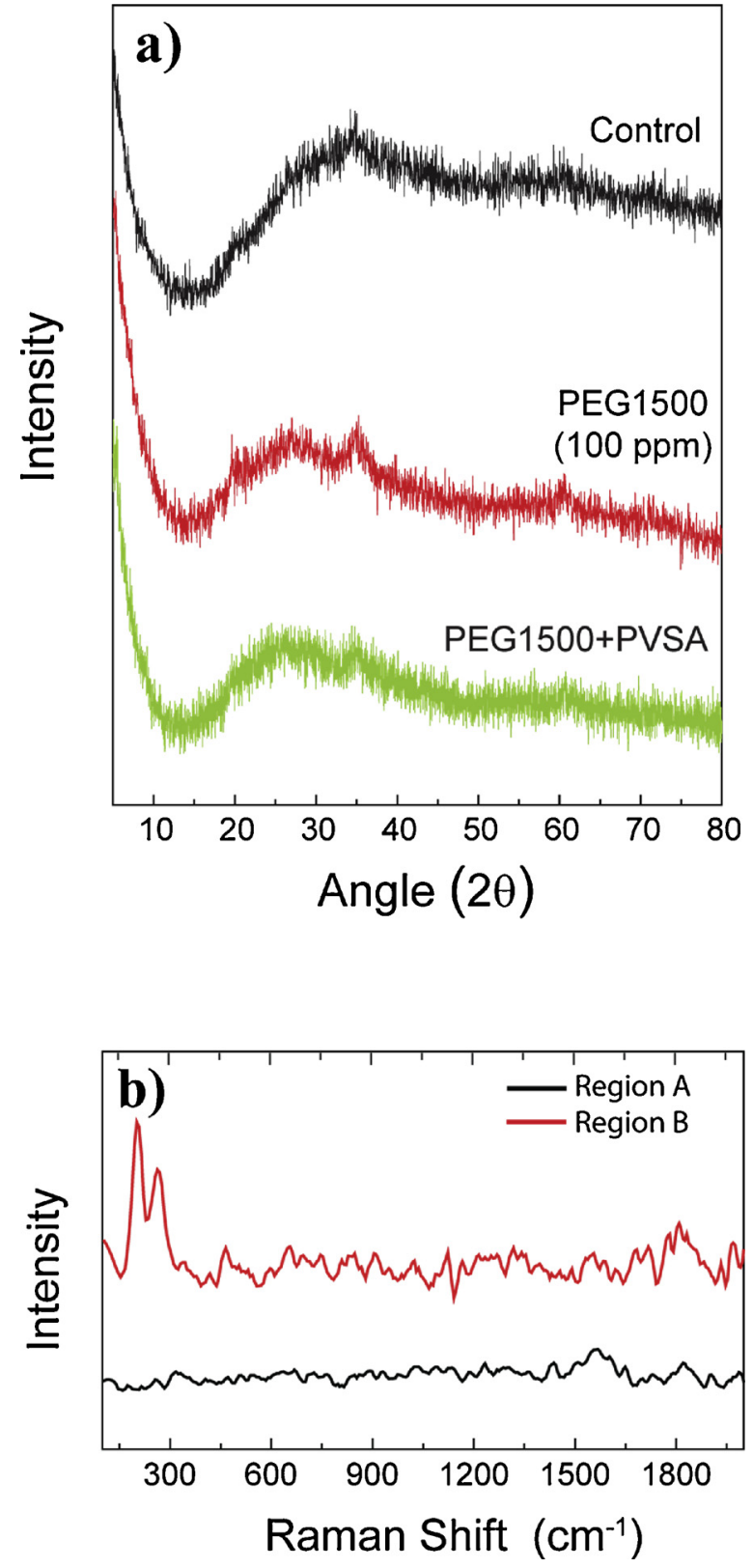

Fig. 3. (a) XRD pattern and (b) Raman spectra of the resulting artificial deposits.

(Kresse and Furthmüller, 1996a, b) software package was used to perform first-principle calculations. We used projector-augmented wave (PAW) (Blöchl, 1994) potentials for ion-electron interaction and the exchange-correlation potential, which is approximated by the Perdew, Burke, and Ernzerhof (PBE) functional (Perdew et al., 1996). Van der Waals interactions were included using the DFT-D2 (Grimme, 2006) approach. The cut-off energy of the plane-wave basis set was chosen to be $500 \mathrm{eV}$. Structure optimizations were performed in vacuum conditions and relaxation criteria were completed when the force on each atom was smaller than $0.1 \mu \mathrm{eV} / \AA$. The binding energy of the ions on the molecules is defined by the formula

$E_{b}=E_{\text {Molecule }}+\mu_{x}-E_{\text {Molecule }+x},(x=F e, M g, C a)$

where $E_{b}$ is the binding energy of the ion on the molecule, $E_{\text {Molecule }}$ is the energy of the molecule, $\mu_{x}$ is the chemical potential of the ion, $E_{\text {Molecule }+X}$ is the total energy of the ion-molecule system. The binding energy of an adatom was calculated in the ground state of the ion-molecule system. To determine the most favorable binding site for the
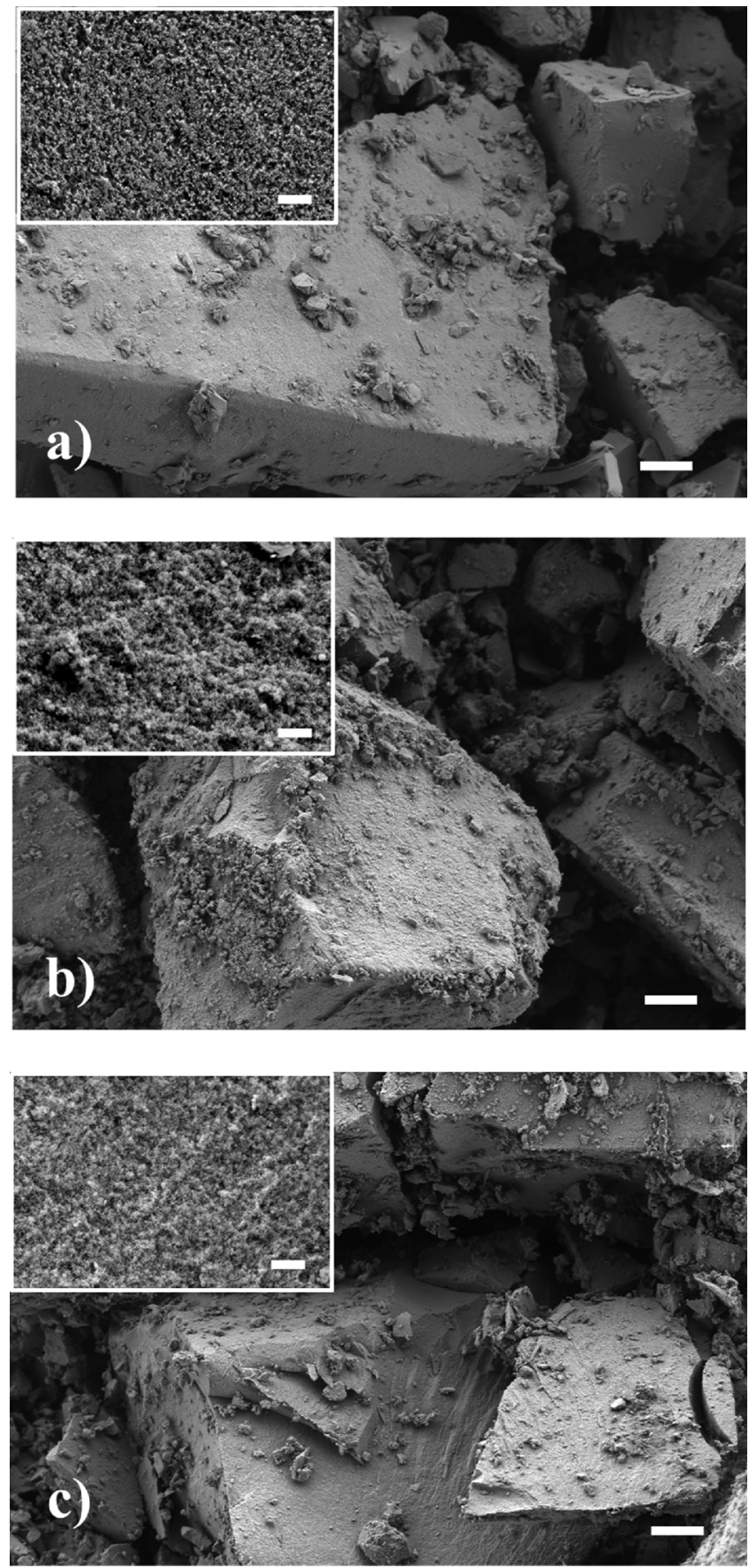

Fig. 4. SEM images of the deposits, which are formed in (a) the absence (control) and (b, c) the presence of the antiscalants (PEG, PEG + PVSA). Scale bars indicate $20 \mu \mathrm{m}$ (insets show higher magnification. Scale bar: $1 \mu \mathrm{m}$ ).

ion bound to the molecule, four calculations assuming different initial geometry were performed.

\section{Results and discussion}

To test the performance of antiscalants, the solubility of molybdate reactive silica is followed in the presence of potential antiscalants during the course of artificial deposit formation. The artificial (Fe, Mg) silicate, which has a similar elemental composition and crystal structure to the natural one was previously obtained by a pressurized autoclave reactor system (Fig. 2) (Çelik et al., 2017). The pH of the initial mixture was measured 7.90 at room temperature. The alkali nature of the initial 
Table 3

Metal:silica ratio of the artificial deposits.

\begin{tabular}{llll}
\hline & $\mathrm{Ca}: \mathrm{SiO}_{2}$ & $\mathrm{Mg}: \mathrm{SiO}_{2}$ & $\mathrm{Fe}: \mathrm{SiO}_{2}$ \\
\hline Control & 0.079 & 0.080 & 0.377 \\
PEG400 & 0.062 & 0.089 & 0.430 \\
PEG1500 & 0.085 & 0.085 & 0.348 \\
PEG6000 & 0.081 & 0.070 & 0.358 \\
PVA40 & 0.053 & 0.078 & 0.388 \\
PVA50 & 0.057 & 0.080 & 0.365 \\
PVA92 & 0.050 & 0.079 & 0.378 \\
\hline
\end{tabular}

mixture originated from the presence of carbonate ions. The conjugate of weak acids (carbonic acid) acted as a base so that the mixture might show a slight increase in $\mathrm{pH}$. After the completion of the reaction, it dropped to 5.86. The diminishing number of carbonate ions may direct the mixture toward an acidic $\mathrm{pH}$. Upon the addition of polymeric chelating agents, the $\mathrm{pH}$ of the leftover dispersion varied. It was reduced to $6.09,5.95$, and 4.47 by the application of PAM, PVSA, and PVPA, respectively. The concentration of silica was found to be $135 \mathrm{mg} / \mathrm{L}$ under the experimental conditions employed (control sample). This concentration is quite close to the one reported in the literature (Demadis et al., 2012a, b). This level of concentration is used as a benchmark for the performance of the antiscalants in the figures with a dashed line.

Fig. 3a shows the XRD pattern of the powder (artificial deposit) prepared in the presence of PEG $1500(100 \mathrm{mg} / \mathrm{L})$ and PEG 1500 $(100 \mathrm{mg} / \mathrm{L})+$ PVSA $(25 \mathrm{mg} / \mathrm{L})$ along with a control sample (no antiscalant polymers). For all samples, the deposits have an amorphous

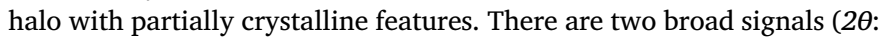
$36^{\circ}$ and $62^{\circ}$ ), which may refer to the (311) and (440) planes of local magnetite $\left(\mathrm{FeO} \cdot \mathrm{Fe}_{2} \mathrm{O}_{3}\right)$ in a deposit as previously reported (Çelik et al., 2017). Note that either the dispersant (PEG 1500) or the chelating agent (PVSA) was ineffective in the presence of magnetite. XRD was also performed for the other deposits and showed the presence of polymers. However, no distinct effect on crystallinity was observed (Fig. S1). The local magnetite formation was also verified by Raman spectroscopy (Fig. 3b). The measurements were carried out on various regions (indicated A and B in the figure) of the deposit (control sample). While no vibrational mode can be identified in Region A, the characteristic $\mathrm{Fe}-\mathrm{O}$ vibration modes $\left(\mathrm{T}_{2 \mathrm{~g}}\right.$ and $\left.\mathrm{E}_{\mathrm{g}}\right)$ are observed at 206 and $266 \mathrm{~cm}^{-1}$ in the other region (Shebanova and Lazor, 2003). Fig. 4 presents an overview of SEM images of the deposits. The samples have a heterogeneous nature such that amorphous silica and metal-amorphous silica associates simultaneously exist in aggregated and agglomerated forms. No distinct difference between the two was observed. An inset of images having a higher magnification $(\mathrm{x} 30000)$ revealed that rigid deposits were formed by spherical-shaped subunits, which were approximately $30 \mathrm{~nm}$ in diameter. Recently, Demadis et al. reported on the internal structure of metal silicates on the basis of example magnesium silicate system (Spinthakia et al., 2018). The authors proposed that the precipitates never correspond to true metal silicates, rather metal ions embedded or adsorbed in amorphous silica. Metal:silica ratios presented in Table 3 may support this hypothesis.

\subsection{Effect of silica stabilizers on solubility (PEG and PVA)}

The dosages were fixed at 25,50 , and $100 \mathrm{mg} / \mathrm{L}$ for all the antiscalants employed. The concentration of molybdate reactive silica for dispersant-type antiscalant trials are given in Fig. 5. It is well established that silicic acid forms a complex with oxygen atoms of ethers and alcohols (Iler, 1952), hence PEG and PVA were employed due to their

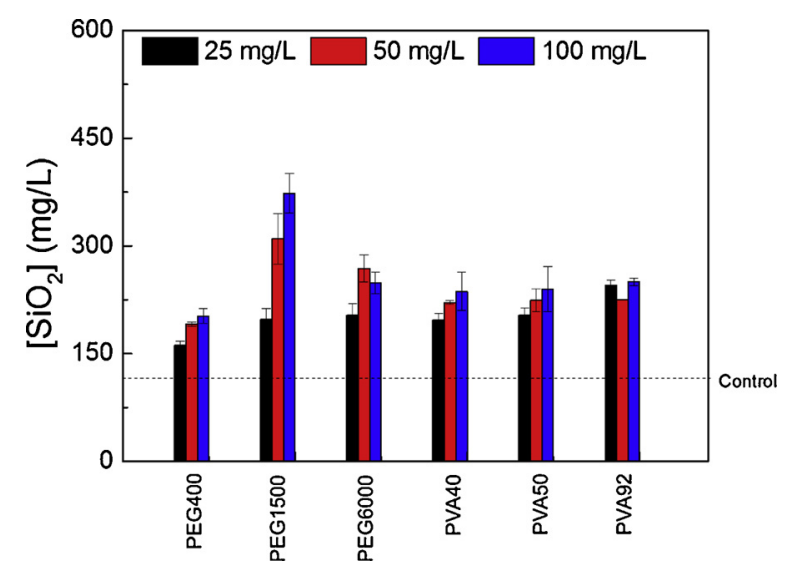

Fig. 5. Concentration of molybdate reactive silica in the presence of polymeric silica stabilizers (PEG and PVA) with different molecular weight. (Dashed line refers to the concentration in the absence of stabilizer).

oxygen containing chemical structure. Two main parameters were studied throughout this work: dosage and molecular weight of the inhibitors. The effect of the former parameter is evident. As a representative example, PEG 1500 enhances the solubility of silica from $200 \mathrm{mg} / \mathrm{L}$ to $375 \mathrm{mg} / \mathrm{L}$ as the dosage of antiscalant increases from 25 to $100 \mathrm{mg} / \mathrm{L}$. Since lone pairs of oxygen moieties are able to form hydrogen bonds with silicic acid derivatives, solubility is positively affected by increasing the dosage of the antiscalant. In other words, the higher the number of oxygen atoms introduced into the system, the greater the amount of silicic acid it is complexed with. A similar result is obtained for PEG 400. However, this trend diminished at a $100 \mathrm{mg} / \mathrm{L}$ dosage of PEG 6000. The level of silica appeared to be lower than the one obtained from the application of 25 and $50 \mathrm{mg} / \mathrm{L}$. The reason for this decrease in silicic acid concentration may be related to the entrapment of the polymer in the deposit structure (Preari et al., 2014). FTIR was used to understand whether the polymeric chain in structure of the artificial deposit remains. At a high molecular weight, the polycondensation onto the polymer backbone continued. Hence, the polymer chain may settle in a deposit (flocculation) due to entrapment by the silica framework (Fig. S2 and S3) that obviously caused a slight decrease in solubility.

The latter parameter, molecular weight, shows a nonlinear relationship with the concentration of molybdate-reactive silica. For instance, at $25 \mathrm{mg} / \mathrm{L}$ of PEG, the silicic acid concentration increases as the molecular weight of the polymers increases. This result is consistent with the literature (Iler, 1952; Preari et al., 2014). However, the solubility increases with PEG 1500 appears to be greater than that of PEG 400 and PEG 6000 at fixed dosages. Note that at $100 \mathrm{mg} / \mathrm{L}$, PEG 1500 shows the greatest silica concentration $(375 \mathrm{mg} / \mathrm{L}$, solubility increase: $51.5 \%$ ) compared to the shorter (PEG 400, $200 \mathrm{mg} / \mathrm{L}$, solubility increase: $15.5 \%$ ) and longer chains (PEG $6000,240 \mathrm{mg} / \mathrm{L}$, solubility increase: $25.7 \%$ ).

Unlike for PEG, the concentration of molybdate-reactive silica fluctuates in the range between $200-250 \mathrm{mg} / \mathrm{L}$ for PVA. Although this level of silicate is higher than the control sample, the efficiency of PVA appears to be lower than that of PEG. The reason for this difference may lie in the chemistry of the monomeric units of the polymer chains. The placement of an oxygen atom in the monomeric structure is considered to be the key issue in the solubility performance (Iler, 1952). It is known that alcohols are more capable of forming hydrogen bonds than their isomeric ethers (e.g., their solubility in water is higher than that of the ethers). Even though PVA can be expected to enhance silica 

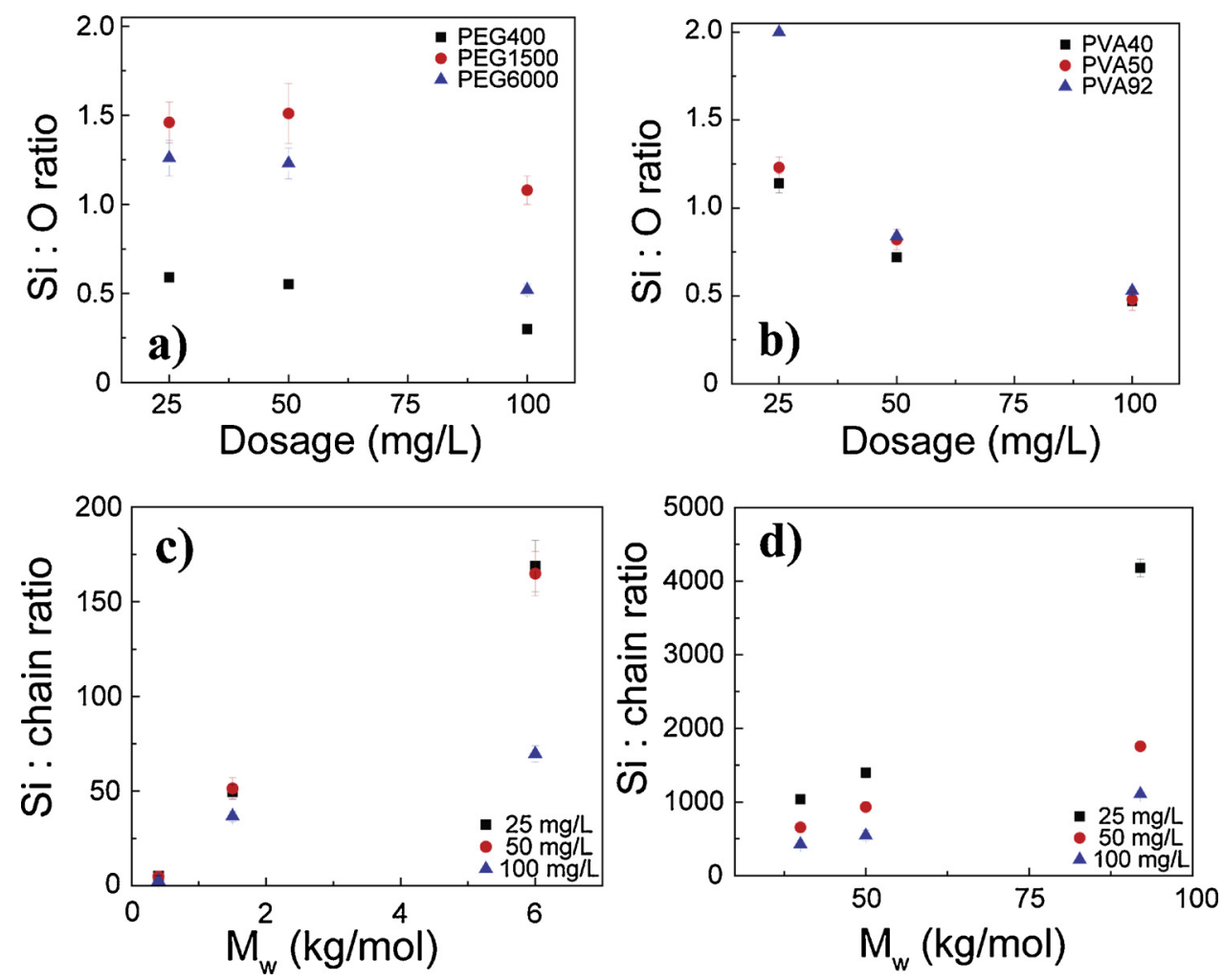

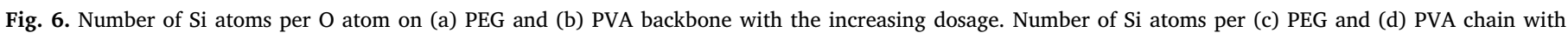
increasing molecular weight.

solubility more than PEG, our experimental results suggest the opposite, that is, PEG increases it more. Oxygen atoms are located on the backbone of PEG; on the other hand, they are sterically hindered on the pendant hydroxyl group of PVA. The long backbone of PVA as a pendant group may cause a steric hindrance for the interaction between silicic acid and oxygen atoms. Note that PVA is obtained by hydrolysis of a polyvinylacetate in alkaline medium such that a certain amount of unhydrolyzed acetate groups is inevitably present on the backbone of the PVA chain.

To provide further information about the interaction between polymer chains and silicic acid derivatives, namely, hydrogen bonding, the number of silicic acid molecules per oxygen moiety (Si:O ratio) was calculated. For instance, PEG 1500 has 34 O atoms $\left(M_{w}\right.$ of polymer $/ M_{w}$ of repeating unit) in one chain and can capture a maximum of $68 \mathrm{Si}(\mathrm{OH})_{4}$ groups at maximum. Therefore, this ratio may hint at the density of hydrogen bonds on the backbone, namely, solubility. Molybdate-reactive silica predominantly consists of monomeric silicic acid; hence, only it was taken into account to keep the calculation simple. For the concentration of mono silicic acid, the data presented in Fig. 5 was used. The molar ratios of the molybdate reactive silica and the polymer were divided into the number of oxygen moieties per chain assuming that all the ethylene oxide moieties are active and interacting evenly with the silicic acids molecules. Figs. $6 \mathrm{a}$ and b show the Si:O ratio at various dosages. In the case of all antiscalant treatments, the $\mathrm{Si}$ :O ratio decreases to $0.5-1.5$, that is, below the numerical limit of two (oxygen has two lone pairs of electrons that two hydrogen atoms can interact with). This result suggests that not all the oxygen atoms undergo hydrogen bonding with silicic acid. The size of the silicic acid molecules is larger than the distance between two consecutive oxygen atoms on the PEG backbone. Thus, silicic acid molecules are sterically hindered from approaching all the available oxygen atoms on the backbone. Independent of the chemistry of polymers, this ratio follows a decreasing trend as the dosage increases. Although a higher number of silicic acid molecules undergoes complexing at higher dosages, the ratio of silicic acid to oxygen atoms decreases with the increase in the dosage of the antiscalant.

The number of $\mathrm{H}$-bonded $\mathrm{Si}$ atoms per polymeric chain was also estimated (Figs. $6 \mathrm{c}$ and d), assuming that the polymeric molecules in a system are of an equal molecular weight. At a fixed dosage, not surprisingly, the degree of polymerization is higher for high molecular weight polymers. The rate of increment (slopes) shows a systematic reduction with increasing dosage. The reason could be related to the morphology of the chains in water. The chains tend to bend, twist and undergo inter/intra molecular entanglement so that some of the Si atoms are hidden in the tangled mass of polymer chain and they will not be available for the interaction.

In addition to $\mathrm{Si}$, the concentration of metal cations was followed, too (Fig. 7). The use of PEG and PVA did not show a significant increase in the concentrations of $\mathrm{Ca}^{2+}$ or $\mathrm{Mg}^{2+}$. Rather their concentration level shows a slight increase compared to the control sample (shown as a dashed line). For instance, in the case of $\mathrm{Fe}^{2+, 3+}$, the concentration in the presence of a polymeric antiscaling agent fluctuated between 2 and $12 \mathrm{mg} / \mathrm{L}$. In the $25 \mathrm{mg} / \mathrm{L}$ PVA92 experiment, the $\mathrm{Fe}^{2+, 3+}$ concentration appears to go up to $12 \mathrm{mg} / \mathrm{L}$ that is about 3 times the concentration in the control.

\subsection{Effect of mixing a metal-chelating agent and dispersants on solubility}

Although the effect of PEG and PVA on the solubility of silica is promising, the elimination of metal cations may further mitigate the 

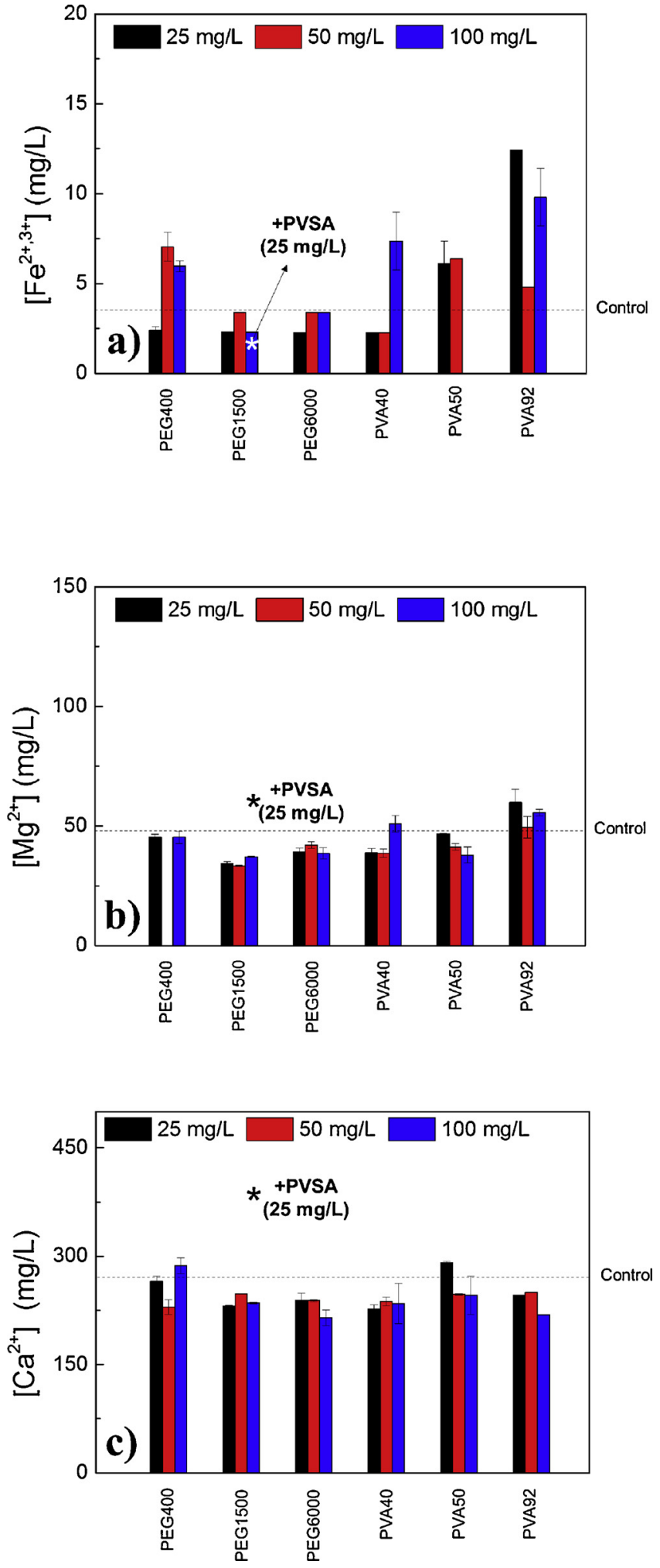

Fig. 7. The concentration of metal ions ((a) $\mathrm{Fe}^{2+, 3+}$, (b) $\mathrm{Mg}^{2+}$, (c) $\mathrm{Ca}^{2+}$ ) in the presence of PEG or PVA at various dosages and molecular weights are given. The dashed line refers to the control sample. The star on the PEG 1500 $/ 100 \mathrm{mg} / \mathrm{L}$ ) refers to the level of the corresponding ions in the presence of PVSA (25 mg/L).
Table 4

Binding energy between various chelating agents and the metal cations.

\begin{tabular}{llll}
\hline $\begin{array}{l}\text { Adatom } \\
\text { Molecule }\end{array}$ & Mg adatom & Ca adatom & Fe adatom \\
\hline Acrylamide & $0.28 \mathrm{eV}$ & $0.72 \mathrm{eV}$ & $1.08 \mathrm{eV}$ \\
Vinyl phosphonic acid & $0.45 \mathrm{eV}$ & $1.03 \mathrm{eV}$ & $1.37 \mathrm{eV}$ \\
Vinyl sulfonic acid & $0.77 \mathrm{eV}$ & $1.47 \mathrm{eV}$ & $1.63 \mathrm{eV}$ \\
\hline
\end{tabular}

formation of metal silicate deposits. Organic acids are known to chelate the cations. So that they can be used as co-antiscalants for PEG 1500, which showed the best results as presented above. For this purpose, the effect of metal-chelating agents (PAM, PVSA, and PVPA) in the presence of PEG 1500 was examined. These agents were chosen because they were found to be active in the reduction of metal silicate scaling in our previous work (Topçu et al., 2017). The concentration of molybdatereactive silica for mixed antiscalants was examined. The addition of PVPA or PAM causes an increase in silica solubility. These two compounds indirectly increase the concentration of molybdate-reactive silica to 365 and $335 \mathrm{mg} / \mathrm{L}$, respectively. The most considerable increase in silica concentration is achieved from PEG 1500 by supporting PVSA (25 mg/L). The concentration of silica increases to $420 \mathrm{mg} / \mathrm{L}$, namely $61.0 \%$ efficiency, when using PVSA co-antiscalant.

To obtain a further understanding of the efficiency of metal-chelating agents, the binding characteristics of the ions with the molecules were investigated by computation via DFT methods. The calculated binding energies are listed in Table 4 . The full relaxation of ions with all the molecules resulted in positive binding energies, hence all the molecules tended to bind with $\mathrm{Mg}^{2+}, \mathrm{Ca}^{2+}$ and $\mathrm{Fe}^{2+}$ ions spontaneously. The binding energy values of $\mathrm{Fe}^{2+}$ indicated that this cation has the strongest bond with all the molecules. On the contrary, $\mathrm{Mg}^{2+}$ was found to form the weakest bond compared to $\mathrm{Ca}^{2+}$ and $\mathrm{Fe}^{2+}$. The selective metal ion-chelating performance of the molecules has also been examined. The best performance was observed in vinylsulfonic acid sodium salt (VSA) for all the ions. The ion-chelating performance of vinyl phosphonic acid (VPA) molecule took second place after the VSA. Lastly, the binding energies of the ions on the acrylamide (AM) molecule were found to be the lowest ones. Nevertheless, even though computational and experimental results are comparable for both VSA and VPA, it may not be very convenient to compare acrylamide to the others with a single calculation due to its various binding sites (Girma et al., 2005). Fig. 8 shows binding sites of the ions captured by the molecules, which are calculated using VASP. All the cations were bound to oxygen sites in the pendant groups. In this regard, it was shown that unsaturated oxygen bonds in the molecules are favorable binding sites for the metal adatoms. To sum up, the results of the computational study are consistent with the experimental ones. Since both divalent and trivalent forms of Fe exist at the end of the reaction, the computation was also performed for $\mathrm{Fe}^{3+}$. According to the binding energy formula, the energy of $\mathrm{Fe}^{3+}$ ion is calculated at the vacuum level meaning that there is no interaction and it has 4 unoccupied electrons in the vacuum ground state. Therefore, $\mathrm{Fe}^{+3}$ ions lead to quite similar structural and electronic features as with $\mathrm{Fe}^{2+}$ ions.

\section{Conclusions}

Metal-silicate scaling is a major issue that needs to be elucidated for water based-system. Instead of employing strong acids, water treatment using soft organic inhibitors is an eco-friendly option for increasing the solubility of silica to prevent deposit formation. This study provides 
a)

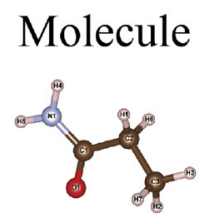

b)<smiles>COC(=O)OC(=O)C(O)OC</smiles>

c)

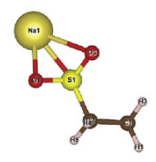

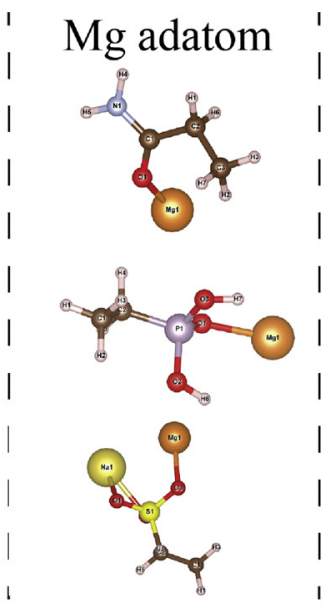

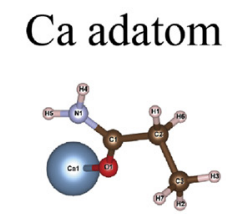

\section{Fe adatom}
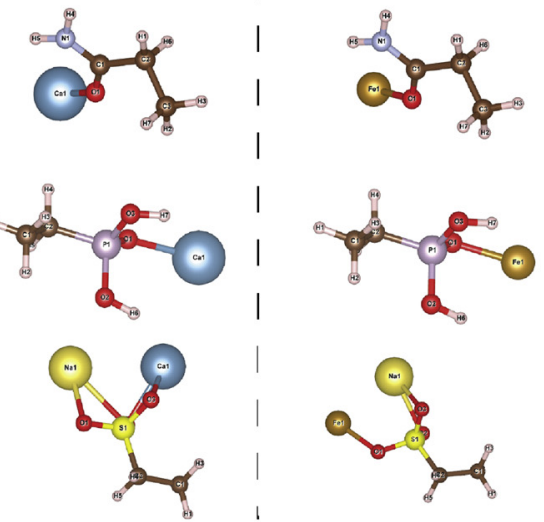

$E_{b} \uparrow$

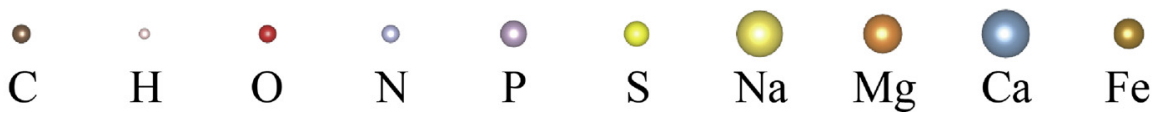

Fig. 8. Schematic representation of binding of the ions captured by the molecules that (a) Acrylamide (b) Vinylphosphonic Acid and (c) Sodium Salt of vinylsulfonic Acid, respectively.

evidence that $\mathrm{Si}(\mathrm{OH})_{4}$ polycondensation is inhibited by ether and alcohol moieties even in the presence of various metal cations $\left(\mathrm{Fe}^{2+}\right.$, $\mathrm{Mg}^{2+}$, and $\mathrm{Ca}^{2+}$ ). The enhancement of silicate solubility is achieved even though the metal cations act as a catalyst for polycondensation. The concentration of molybdate reactive silica increased from $130 \mathrm{mg} /$ L to 375 when PEG 1500 (100 mg/L) was employed. This level of concentration is further increased to $420 \mathrm{mg} / \mathrm{L}$ by the chelating performance of PVSA $(25 \mathrm{mg} / \mathrm{L})$. The mixture of PEG and PVSA is an environmentally friendly approach to decrease of metal silicate formation observed not only in hot (geothermal and petroleum wells) but also in cold industrial water systems.

\section{Funding sources}

This research is funded by The Scientific and Technological Research Council of Turkey (Tubitak) with a project number 114Z940.

\section{References}

Baba, A., Demir, M.M., Koç, G.A., Tuğcu, C., 2015. Hydrogeological properties of hypersaline geothermal brine and application of inhibiting siliceous scale via $\mathrm{pH}$ modification. Geothermics 53, 406-412.

Blöchl, P.E., 1994. Projector augmented-wave method. Phys. Rev. B 50, 17953.

Çelik, A., Topçu, G., Baba, A., Akdogan, Y., Şentürk, U., Demir, M.M., 2017. Experimental modeling of silicate-based geothermal deposits. Geothermics 69, 65-73.

Coradin, T., Eglin, D., Livage, J., 2004. The silicomolybdic acid spectrophotometric method and its application to silicate/biopolymer interaction studies. J. Spectrosc. 18, 567-576.

Corsi, R., 1986. Scaling and corrosion in geothermal equipment: problems and preventive measures. Geothermics 15, 839-856.

Danilovtseva, E.N., Pal'shin, V.A., Likhoshway, Y.V., Annenkov, V.V., 2011. Condensation of silicic acid in the presence of co (1-vinylimidazole-acrylic acid). Adv. Sci. Lett. 4, 616-621.

Demadis, K.D., Neofotistou, E., 2007. Synergistic effects of combinations of cationic polyaminoamide dendrimers/anionic polyelectrolytes on amorphous silica formation: a bioinspired approach. Chem. Mater. 19, 581-587.

Demadis, K.D., Ketsetzi, A., Pachis, K., Ramos, V.M., 2008. Inhibitory effects of multicomponent, phosphonate-grafted, zwitterionic chitosan biomacromolecules on silicic acid condensation. Biomacromolecules 9, 3288-3293.

Demadis, K.D., Mavredaki, E., Somara, M., 2011a. Additive-driven dissolution enhancement of colloidal silica. 1. Basic principles and relevance to water treatment. Ind. Eng. Chem. Res. 50, 12587-12595.

Demadis, K.D., Mavredaki, E., Somara, M., 2011b. Additive-driven dissolution enhancement of colloidal silica. 2. Environmentally friendly additives and natural products.
Ind. Eng. Chem. Res. 50, 13866-13876.

Demadis, K.D., Ketsetzi, A., Sarigiannidou, E.-M., 2012a. Catalytic effect of magnesium ions on silicic acid polycondensation and inhibition strategies based on chelation. Ind. Eng. Chem. Res. 51, 9032-9040.

Demadis, K.D., Tsistraki, A., Popa, A., Ilia, G., Visa, A., 2012b. Promiscuous stabilisation behaviour of silicic acid by cationic macromolecules: the case of phosphoniumgrafted dicationic ethylene oxide bolaamphiphiles. RSC Adv. 2, 631-641.

Demir, M.M., Baba, A., Atilla, V., İnanl1, M., 2014. Types of the scaling in hyper saline geothermal system in northwest Turkey. Geothermics 50, 1-9.

Gallup, D.L., 1998. Aluminum silicate scale formation and inhibition (2): scale solubilities and laboratory and field inhibition tests. Geothermics 27, 485-501.

Gallup, D.L., 2002. Investigations of organic inhibitors for silica scale control in geothermal brines. Geothermics 31, 415-430.

Gallup, D.L., 2009. Production engineering in geothermal technology: a review. Geothermics 38, 326-334.

Gallup, D.L., Barcelon, E., 2005. Investigations of organic inhibitors for silica scale control from geothermal brines-II. Geothermics 34, 756-771.

Girma, K., Lorenz, V., Blaurock, S., Edelmann, F.T., 2005. Coordination chemistry of acrylamide. Coord. Chem. Rev. 249, 1283-1293.

Girma, K., Lorenz, V., Blaurock, S., Edelmann, F.T., 2006. Coordination chemistry of acrylamide 3: synthesis, crystal structure and IR spectroscopic properties of dichlorotetrakis (O-acrylamide) copper (II), [Cu (O-OC (NH 2) CH. Inorg. Chim. Acta 359, 364-368.

Grimme, S., 2006. Semiempirical GGA-type density functional constructed with a long-range dispersion correction. J. Comput. Chem. 27, 1787-1799.

Icopini, G.A., Brantley, S.L., Heaney, P.J., 2005. Kinetics of silica oligomerization and nanocolloid formation as a function of $\mathrm{pH}$ and ionic strength at $25 \mathrm{C}$. Geochim. Cosmochim. Acta 69, 293-303.

Iler, R.K., 1952. Association between polysilicic acid and polar organic compounds. J. Phys. Chem. -U. S. 56, 673-677.

Iler, K.R., 1979. The Chemistry of Silica. John Wiley \& Sons, New York.

Kresse, G., Furthmüller, J., 1996a. Efficiency of ab-initio total energy calculations for metals and semiconductors using a plane-wave basis set. Comp. Mater. Sci. 6, 15-50.

Kresse, G., Furthmüller, J., 1996b. Efficient iterative schemes for ab initio total-energy calculations using a plane-wave basis set. Phys. Rev. B 5411169.

Palencia, M., Rivas, B.L., Pereira, E., 2009. Metal ion recovery by polymer-enhanced ultrafiltration using poly (vinyl sulfonic acid): fouling description and membrane-metal ion interaction. J. Membr. Sci. 345, 191-200.

Perdew, J.P., Burke, K., Ernzerhof, M., 1996. Generalized gradient approximation made simple. Phys. Rev. Lett. 77, 3865.

Porcelli, N., Judd, S., 2010. Chemical cleaning of potable water membranes: a review. Sep. Purif. Technol. 71, 137-143.

Potapov, V., Kashpura, V., Alekseev, V., 2001. A study of the growth of deposits in geothermal power systems. Therm. Eng. 48, 395-400.

Preari, M., Spinde, K., Lazic, Jl., Brunner, E., Demadis, K.D., 2014. Bioinspired insights into silicic acid stabilization mechanisms: the dominant role of polyethylene glycolinduced hydrogen bonding. J. Am. Chem. Soc. 136, 4236-4244.

Rivas, B.L., Pereira, E., Gallegos, P., Homper, D., Geckeler, K.E., 2004. Metal ion binding capability of the water-soluble poly (vinyl phosphonic acid) for mono-, di-, and trivalent cations. J. Appl. Polym. Sci. 92, 2917-2922. 
Shebanova, O.N., Lazor, P., 2003. Raman spectroscopic study of magnetite (FeFe2O4): a new assignment for the vibrational Spectrum. J. Solid State Chem. 174, 424-430.

Spinde, K., Pachis, K., Antonakaki, I., Paasch, S., Brunner, E., Demadis, K.D., 2011.

Influence of polyamines and related macromolecules on silicic acid polycondensation: relevance to "soluble silicon pools"? Chem. Mater. 23, 4676-4687.

Spinthakia, A., Petratosa, G., Matheisb, J., Haterb, W., Demadis, K.D., 2018. The precipitation of "magnesium silicate" under geothermal stresses. Formation and characterization. Geothermics 74, 172-180.

Topçu, G., Celik, A., Baba, A., Demir, M.M., 2017. Design of polymeric antiscalants based on functional vinyl monomers for (Fe, Mg) silicates. Energy Fuel 31, 8489-8496.

Zhang, B.-R., Chen, Y.-N., Li, F.-T., 2011. Inhibitory effects of poly (adipic acid/amineterminated polyether D230/diethylenetriamine) on colloidal silica formation. Colloid Surface A 385, 11-19. 